\title{
РОЛЬ ГРАЖДАНСКОЙ ИДЕНТИЧНОСТИ МОЛОДЕЖИ В ПРОЦЕССЕ КОНСОЛИДАЦИИ РОССИЙСКОГО ОБЩЕСТВА
}

\section{Власов Сергей Николаевич}

студент

ФГБОУ ВО «Ростовский государственный медицинский университет»

\begin{abstract}
Аннотация: Автор статьи отмечает, что многие страны, которые обладают этнокультурным составом населения, сталкиваются с тем, что приходится регулировать межэтнические отношения граждан. Российское общество не является исключением, что подталкивает искать способы регулирования возникающего вопроса. Автор работы в статье рассматривает роль, которую играет гражданская идентичность молодежи в процессе консолидации российского общества. По мнению автора, данный механизм способствует достижению межнационального согласия в государстве. В настоящее время современный этап формирования гражданской идентичности российской молодежи характеризуется осознанием существования объединяющих ценностей, основанных на принципах патриотизма, духовности, правовой культуры.
\end{abstract}

Ключевые слова: идентичность, консолидация, российское общество, молодежь, идентичность молодежи.

\section{THE ROLE OF CIVIC IDENTITY OF YOUTH IN THE PROCESS OF CONSOLIDATION OF RUSSIAN SOCIETY}

\section{Vlasov Sergey Nikolaevich}

\begin{abstract}
The author of the article notes that many countries that have an ethno-cultural composition of the population are faced with the fact that it is necessary to regulate interethnic relations of citizens. Russian society is no exception, which pushes us to look for ways to regulate the emerging issue. The author of the article examines the role played by the civic identity of youth in the process of consolidation of Russian society. According to the author, this mechanism contributes to the achievement of interethnic harmony in the state. At present, the modern stage of the formation of the civic identity of Russian youth is
\end{abstract}


characterized by awareness of the existence of unifying values based on the principles of patriotism, spirituality, and legal culture.

Key words: identity, consolidation, Russian society, youth, youth identity.

Страны, которые имеют население с разным этнокультурным составом, активно обращают внимание на регулирование межэтнических отношений среди населения. На территории Российской Федерации проживает большое количество населения с разным этническим и национальным составом $[1 ; 2]$. Являясь одним из крупнейших полиэтнических государств мира, Российская Федерация сталкивается с межэтническими противоречиями населения, поэтому одной из стратегических задач государства является укрепление единства страны, консолидация российского общества [3]. Актуальность данного вопроса очень значима для тех регионов, которые исторически являются полиэтничными.

Поскольку российское общество является обладателем особого историко-культурного код, который основан на уважении этнических традиций всех народов, проживающих в России, то с укреплением единства страны возникают определенные трудности. В связи с чем и возникает вопрос о механизмах, которые помогают в консолидации российского общества. К одним из таких механизмов, на наш взгляд, относится гражданская идентичность.

Отечественные исследователи проявляются большой интерес к теме формирования гражданской идентичности. Известный российский ученый Л.М. Дробижева в течение своей научной карьеры занималась исследованиями межнациональных отношений изучала факторы, способствующие поддержанию межэтнического согласия в России [4; 5]. Большую роль в исследовании межэтнических отношений в молодежной среде играют работы В.А. Тишкова. В.А. Тишков обращается к оценкам толерантности и нетерпимости студенческой молодежи [6]. Межнациональные отношения на Юге России также вызывает большой когнитивный интерес у научного сообщества [7; 8].

Анализ научно-исследовательских источников по выбранному проблемному полю исследования показывает, что исследование идентичности населения России, в том числе и молодежи, является актуальной темой исследования. На наш взгляд, особую социальную и научную значимость заключают в себе исследования, которые рассматривают установки молодежи, 
особенно той молодежи, которая проживает на территории полиэтнических районов. Связано это с тем, что молодежь является наиболее активной социально-демографической группой, которая участвует в социальной и политической жизни страны. То, какое участие российская молодежь будет принимать в интерпретации культурного кода России и налаживании межнациональных отношений своей страны, будет отражаться на консолидации российского общества в целом.

Обращаясь к Стратегии государственной национальной политики России, мы видим, что к стратегическим целям российского государства относится обеспечение приверженности граждан к целостности территории, на которой они проживают, сплоченности населения, консолидации общества. Важную роль в решении перечисленных задач выполняет идентичность, так как она позволяет реализовать не только перечисленные задачи, но и необходима гражданам для поддержания благоприятного социальнопсихологического самочувствия, что в целом способствует общественному развитию России. Под гражданской идентичностью понимается самоидентификация себя с гражданами страны и той территории, на которой ты проживаешь. В рамках гражданской идентичности человек сознательно фиксирует«наличие определенных представлений о государстве, стране, образа Мы, чувства общности, солидарности, ответственности за происходящее в стране» [5].

Как показывает вторичный анализ исследований, изучению вопросов, связанных с гражданской идентичностью посвящен блок крупномасштабных проектов RLMS-HSE и ИС РАН. Если смотреть результаты эмпирических замеров, полученных в рамках данных исследований, то мы видим, что молодые люди не так часто проявляют гражданскую идентичность: чуть более $1 / 3$ молодежи идентифицирует себя с людьми той же национальности, и около $1 / 3$ - со всеми гражданами России. Чаще всего самоидентификация молодых людей происходит с теми показателями, которые молодежь постоянно ощущает в повседневной жизни. К таким показателям можно отнести профессиональный критерий. Исходя из этого, на наш взгляд, важно развивать и поддерживать на государственном уровне показатели гражданской идентичности. Например, в настоящее время России активно реализуются мероприятия Федеральным агентством по делам национальностей. ФАДН призвано осуществлять меры, направленные на укрепление единства многонационального народа Российской Федерации, обеспечение 
межнационального согласия, этнокультурного развития народов Российской Федерации.

Таким образом, проведенный нами анализ позволяет сделать вывод, что формирование гражданской идентичности в молодежной среде позволяет государству наиболее эффективно регулировать межэтнические конфликты среди населения, а также достигать межнационального согласия и консолидации российского общества. В настоящее время современный этап формирования гражданской идентичности российской молодежи характеризуется осознанием существования объединяющих ценностей, основанных на принципах патриотизма, духовности, правовой культуры; признанием активной роли государства в процессе структурирования гражданской сферы общества; формированием личности, обладающей социальной зрелостью.

\section{Список литературы}

1. Официальный сайт Всероссийская перепись населения 2010 [Электронный pecypc] URL: http://www.gks.ru/free_doc/new_site/perepis2010/ croc/perepis_itogi1612.htm (дата обращения: 09.02.2022 г.).

2. Сайт РосИнфоСтат [Электронный ресурс] URL: hhttps://rosinfostat.ru/ natsionalnyj-sostav/\#i-2 (дата обращения: 09.02.2022 г.)

3. Указ Президента РФ от 19.12.2012 № 1666 «О стратегии государственной национальной политики Российской Федерации и на период до 2025 г.» [Электронный документ] URL: http://kremlin.ru/acts/bank/36512 (дата обращения: 09.02.2022 г.).

4. Дробижева Л.М. Гражданская идентичность как условие ослабления этнического негативизма // Мир России. - 2017. - Т. 26. № 1. - С. 7-31.

5. Дробижева Л.М. Общероссийская идентичность и уровень межнационального согласия как отражение вектора консолидационных процессов // Социологические исследования. - 2017. - № 1. - С. 25-36.

6. Тишков В.А., Бараш Р.Э., Степанов В.В. Идентичность и жизненные стратегии студенчества в России // Социологические исследования. - 2017. № 8. - С. 81-87.

7. Артамонова Я.В., Мищенко Д.Н., Узунова О.Ю., Люев А.Х. Межнациональное согласие в сознании и повседневной культуре молодежи 
Ростовской области в контексте миграционных процессов на Юге России // Гуманитарий Юга России. - 2019. - Т. 8. - № 5. - С. 248-259.

8. Волков Ю.Г., Лубский А.В., Воденко К.В., Войтенко В.П., Денисова Г.С. Институциональные практики в межэтническом и межрелигиозном взаимодействии на Юге России: междисциплинарный анализ и оценка потенциала использования в укреплении общероссийской идентичности. - Ростов-на-Дону, -2018.- 304 с.

(C) С.Н. Власов, 2022 